\title{
Research on the Value of Yoga Fitness and the Market Development
}

\author{
Min Li \\ Jiangxi Science \& Technology Normal University, Jiangxi Province, Nanchang, 330013
}

Keywords: Yoga, Fitness Value, Marketization

\begin{abstract}
Yoga as the representative sport advocating the natural fitness theory, because of its good fitness value and be loved and respected by the world's people, it has gradually become another noun of healthy fashion. However, according to the survey of Chinese current practice of yoga crowd, it shows that $95 \%$ of them are women. Therefore, the development of yoga fitness market needs to be further open. This paper analyzes the health value of yoga fitness by taking yoga fitness as the research background. Finally, according to the future research trends of yoga fitness, we need to explore the development of yoga fitness market strategy to enhance the yoga fitness project visibility and build a healthy and harmonious society.
\end{abstract}

\section{Introduction}

In the continuous improvement of quality of life at the same time, more and more people attention to physical and mental health. Changes in the concept of the audience promote the development of the market fitness industry. Yoga was born in AD 300 years ago in India, is a change through the body of the fluency of the body, the spirit of the natural unity of the realm. The term "yoga" is translated by Indian Sanskrit. According to the 2016 "Sports and Fitness Consumer Data Analysis Report" data show that: yoga and dance is the most popular fitness program in 2016. The purpose of people's fitness is generally divided into three kinds: weight-loss fitness, decompression fitness, physical fitness. The fitness crowd is generally between 22-50 years of age social groups, of which $75 \%$ for young people, yoga as a weight-loss and decompression as one of the comprehensive fitness program, more in line with the fitness needs of young people. Therefore, yoga this fitness project in the entire fitness market has a larger market prospects. The article "explore the value of yoga fitness and market development strategy" as the research topic, taking the depth of research [1].

\section{The Fitness Value of Yoga}

\subsection{Body Shaping}

Choose the majority of fitness for the young women, in the process of yoga exercise, through breathing, meditation, and posture and other practice methods to achieve relaxed body, body shape, diameter and other activities. Different from the mechanical exercise, yoga breathing method through the regulation of the atmosphere, so that the body more symmetrical lines. At the same time in the process of muscle soothing, so that the pressure is released to improve the mental outlook of fitness. People are under too much stress at the same time, the nerves in a tight state, resulting in the body cannot function properly functioning, for example: cannot be normal sleep, eating habits are affected. These actions will make people's physical and mental changes have occurred, thus affecting people's employment development. And yoga this fitness exercise can effectively improve the development of the status quo. The reason why the number of fitness each year will be a substantial increase, because people's aesthetic concept began to change in the process of people's employment, not only requires people to have a certain capacity, while some jobs on people's stature Appearance also made a certain request. Yoga this fitness project with the body shape of this 
effect, is conducive to the protection of people's health, broaden the people's employment. Have an important fitness value [2].

\subsection{Improve the Character}

In Addition to this effect of self-cultivation, Yoga is also support the function. Meditation makes it possible for people to forget the complex environment in which they live, and to make people feel calm and calm by replacing the way of thinking and psychological comfort. Fast-paced lifestyle increases the friction between people, because people are impulsive and constitute a gradual increase in the number of crimes. The harmonious development of society In addition to coordinating the harmony between the various productions projects, but also need to further enhance people's cultural quality. Yoga to improve the character of the health value of this effect in addition to reflect the people's lives, employment development process, but also reflected in the promotion of their own health in this regard. Medical research shows that: impulsive irritability easily lead to cerebral congestion, liver damage and other diseases, yoga exercise process, through the respiratory regulation and music, environmental and other factors of hypnosis, so that people forget the trouble, calm mood [3].

\section{The Market Development of Yoga Fitness}

\subsection{Use New Media Platform to be Widely Publicized}

Choose yoga fitness mostly 22-36 years old between women, this part of the crowd mainly for office workers, housewives, postpartum baby and so on. To promote the development of yoga this fitness project, the first step is the need for different groups of people, the use of new media, an effective platform, through different channels for online and offline joint promotion. For example, for young people this group, you can We-Chat, micro-blogging and other new media, focusing on the introduction of thin decompression yoga classes, and for housewives this group, through We-Chat, television and other platforms, launched health beauty yoga classes. Finally, for the postpartum mother this group, you can through the We-Chat, QQ these two channels, the introduction of postpartum slimming and other yoga classes. By satisfying the consumption habits of different audiences, targeted advertising promotion, enhance brand awareness. In a brand or a fitness project market development process, to expand the visibility of fitness projects is essential, only to deepen the audience's impression of this fitness project in order to further guide the audience to try [4].

\subsection{The Perfection of the Legal Guarantee System and the Supervision and Management Mechanism}

Yoga fitness has achieved market-oriented development, the need to establish a certain legal supervision mechanism to regulate the development of yoga fitness institutions. At present, most of Chinese yoga industry is self-employed, so we need to establish a comprehensive yoga industry market economy management system, regulate the operation of individual business behavior, and create a good business environment. This in the process of market development, called "the establishment of brand image", a fitness project brand image is good or bad, determines the level of audience loyalty. Yoga fitness belongs to the health industry, so it gives the brand image must be formal, healthy and positive. If there is no legal supervision, yoga individual operators will be more based on their own subjective awareness of self-management, it will give yoga fitness project to shape a number of images, including positive, negative, positive image, a variety of negative images. Diversified development of the state makes the development of yoga fitness market decentralized hinders the development of yoga fitness. Legal protection system and the improvement of supervision and management mechanism, so that Chinese individual yoga operators to form a unified development situation, is conducive to shaping a good brand image, enhance audience loyalty, and strengthen the yoga fitness market development momentum. 


\subsection{The Depth Mining of the Yoga Fitness Audience}

According to the article above the study shows that: yoga fitness to the audience as between 22-36 years old women, while ignoring the children and men this group. The reason why the formation of such a situation, because the yoga curriculum, there is no process for men to thin. Men and women in the physiological and psychological structure there is a big gap, therefore, to dig out the depth of the yoga fitness audience, first of all the first step need to add for men and children yoga classes. For example: the establishment of parent-child yoga project, male slimming items. Male fitness is to increase the muscle's hardness by increasing the hardness of the muscles. For children, this health course can be corrected by designing child care and childhood. In the field of marketing, this strategy is called: by increasing the form of products, broaden the audience [5].

Yoga fitness as a free from religious, geographical environment, human environment constraints and everyone can participate in fitness activities, in order to increase the number of audiences, need a new field, open yoga fitness program to attract new audiences. Through practical action to change people's minds, in people's traditional ideas, yoga is a flexible fitness program that is only suitable for women. Just as the dance can only be as a female hobby, by the traditional thinking of the restrictions, yoga market development area is smaller. The development of the status quo for the future development of yoga market process, there are advantages and disadvantages. The current narrow areas of development for the future development of yoga provide more development channels and upside. So the depth of the yoga fitness audience in addition to the addition of new fitness projects, but also need to change people's traditional concept, so that the new fitness program can be recognized by the market, further withdrawal of yoga fitness development, build a harmonious, healthy of society.

\section{Conclusion}

In summary, yoga fitness is conducive to people shaping the body, improve character, with important health value. But the yoga fitness from the beginning of the birth of the formation of slow market development, small audience and other development status, resulting in yoga fitness market competitiveness gradually weakened, to change the state of social development, and strengthen the yoga fitness market development momentum, the media platform is widely publicized, the legal protection system and the improvement of supervision and management mechanism, the depth of the yoga fitness audience digging these three aspects, so that yoga fitness brand awareness, brand image, the number of audience has been fully promoted, so that people from the psychological to stature from inside to outside. To further promote the yoga project more healthy and orderly development, and guide the community to get actively and healthy development.

\section{References}

[1] Xiang Guangchun. Reflections on Ideological and Political Education of Higher Vocational College Students Based on the Integration of Production and Teaching [J]. Journal of Zhejiang Industry and Trade Vocational and Technical College, 2017, 17 (01): 20-24.

[2] Zhu Jia. "Combination of work and study" model and higher vocational colleges ideological and political education integration and development [J]. Journal of Vocational College, 2016, (04): 107-110.

[3] Du Chunmei. Study on the Socialization Teaching Reform of Ideological and Political Education in Higher Vocational Colleges under the Mode of Combination of Work and Study [J / OL]. Journal of Qingdao Vocational and Technical College, 2015, 28 (06): 40-43 + 56.

[4] Di Yue.Study on the Innovation of Ideological and Political Education Mode of Higher Vocational College Students from the Perspective of "Combination of Work and Study[J]. Enterprise Guide, 2015, (01): $123+121$.

[5] Zhou Wendong. Analysis of ideological and political education reform of vocational students under the combination of work and study[J]. Journal of Hubei Correspondence University, 2014, 27 (07): 16-17. 